LBL-34616

UC 109

\title{
QUARTERLYREPORT
}

July 1, 1993 - September 30, 1993

\section{FUNDAMENTAL STUDIES OF THE MECHANISM OF CATALYTIC REACTIONS WITH CATALYSTS EFFECTIVE IN THE GASIFICATION OF CARBON SOLIDS AND THE OXIDATIVE COUPLING OF METHANE}

\author{
Principal Investigators: Heinz Heinemann \\ Center for Advanced Materials \\ Materials Sciences Division \\ Lawrence Berkeley Laboratory \\ University of California \\ Berkeley, CA 94720
}

Gabor A. Somorjai

Dale L. Perry

This work was supported by the Assistant Secretary for Fossil Energy, Office of Technical Coordination, U.S. Department of Energy under Contract DE-AC0376SF00098, through the Morgantown Energy Technology Center, Morgantown, West Virginia 26505. 


\section{TABLE OF CONTENTS}

\section{Page}

I. Task Description for FY 1993

II. Introduction

III. Highlights 3

a) Catalytic Steam Gasification of Coals, Chars and Cokes 3

b) Oxidative Methane Coupling and Partial Oxidation 4 of Methane

c) Synthesis and Characterization of Catalysts

IV. Progress of Studies

a) Catalytic Steam Gasification of Coals, Chars and Cokes 5

b) Oxidative Methane Coupling and Partial Oxidation of Methane

c) Synthesis and Characterization of Catalysts

ATTACHMENT: $\quad \mathrm{Ca}(1-x) \mathrm{Ni}_{x} \mathrm{O}$ Catalytic Thin Films Prepared by Pulsed Laser Deposition 


\section{Task Description for FY 1993}

Task 1: Work on catalytic steam gasification with chars and coals will be extended from atmospheric to elevated pressures using the newly built pressure unit. The novel finding that coking of petroleum in the presence of small amounts of caustic greatly improves the gasification rates and characteristics of the coke will be extended to chars. The chars will be prepared by charing coals in the presence of minor amounts of caustic and the resulting chars will be steam gasified in the absence and presence of catalysts.

Task 2: In the oxidative coupling of methane over ternary catalysts, a large number of factors remain poorly understood and must be investigated to improve results and move them into the commercially interesting area. Emphasis will be placed on low temperature coupling and on the oxidative production of syngas from methane at low temperature. Work on the CRADA between LBL and Orion ACT will continue and will be expanded to include methane coupling to higher hydrocarbons in a membrane reactor. Isotope studies will be undertaken to better understand the nature of the active catalyst sites.

Task 3: Experimental work will continue on the synthesis of the mixed catalyst, and they will be characterized by a number of techniques, including elemental analyses, $x$-ray diffraction, and surface area determination. Scanning electron microscopy will be used to monitor the variations of the surface morphology as a function of the preparative route. X-ray photoelectron, Auger, Raman and infrared spectroscopy will be used to study chemical and bonding aspects of the catalysts.

\section{Introduction}

Work during the fourth quarter of FY93 was slowed down by two factors: one of the postdoctoral fellows on the program left the project after two years participation to accept an industrial position, and training of a new co-worker will require some time; most of the available funds for the methane conversion project were exhausted during the first three quarters because of the need to modify equipment.

\section{Highlights}

a) Catalytic Steam Gasification of Coals and Cokes

- Charring of coal in the presence of alkali was optimized at a level of about $1 \mathrm{wt} \%$. Water washing chars prepared with higher alkali content resulted in gasification rates of about the same magnitude as that of chars prepared with 1 wt\% $\mathrm{NaOH}$. 
- Gasification rates of chars prepared by charring coal in the presence of $\mathrm{NaOH}$ were further enhanced by using steam containing small amounts of entrained $\mathrm{NaOH}$.

- A large number of tri-metallic catalysts were tested for catalytic steam gasification.

b) Oxidative Methane Coupling

- Work has continued with a reactor design comprising a protonconducting perovskite oxide membrane. There is relatively little previous work reported in the literature on this type of system.

Hydrogen ion abstraction from methane occurs by surface $\mathrm{O}^{\circ} \mathrm{cn}$ the membrane surface

- Difficulties had been encountered in designing a reactor which would not be subject to air leaks at high temperature. These have now been overcome.

- $\quad$ Sintered zirconium based perovskite discs have been prepared but are subject to tiny cracks allowing a small amount of gas intermixing across the membrane.

- Even with imperfect membranes, coupling products are observed on the methane side in small quantities, justifying the basic assumptions of the process.

- Work has started on a two-step process in which methane is catalytically decomposed to $\mathrm{C}$ and $\mathrm{H}_{2}$ and the carbonaceous material on the catalyst is then either converted with water to syngas or hydrogenated to higher hydrocarbons.

c) Synthesis and Characterization of Catalysts

- Studies on the synthesis of the catalysts in different forms were continued, especially as they related to the fabrication of films of the catalytic materials.

- Magnetochemical studies have been continued with regard to using this experimental approach to study the electronic and magnetic differences among different catalysts. 


\section{Progress of Studies}

\section{a) Catalytic Steam Gasification of Coals, Chars and Cokes}

During the fourth quarter of FY93, additional studies were undertaken to quantify the effect of adding alkali to coal during charring. Figure 1 shows that the rate of gasification of Ill\#6 char prepared by charring the coal in the presence of different amounts of $\mathrm{NaOH}$ increases with the amount of $\mathrm{NaOH}$ used between 0 and $2 \mathrm{wt} \%$. However, most of the improvement occurs with the addition of small amounts of alkali, while doubling the proportion of alkali from 0.9 to $1.7 \%$ gives a small additional improvement.

In fact it appears that 0.8 to $1 \%$ alkali during charring is optimal. This is demonstrated in Figure 2. The chars prepared in the presence of $\mathrm{NaOH}$ were water washed and extracted at room temperature until the water was alkali free, dried and then gasified. Figure 2 presents the same data as Figure 1 but additionally shows the gasification rate at $640^{\circ} \mathrm{C}$ for the water washed chars. The water washed char originally prepared with $.85 \% \mathrm{NaOH}$ had the same gasification rate as before water washing, while the gasification rate of the char originally prepared with $1.7 \% \mathrm{NaOH}$ dropped to the level of the $.85 \% \mathrm{NaOH}$ containing char after water washing. This may be interpreted as an indication of about $1 \%$ alkali being incorporated into the char in a water insoluble form.

The last quarterly report (LBL-34250) showed initial data in Figures 5 and 6 of that report indicating that raw char (prepared without alkali) could be gasified at higher rates when a dilute aqueous solution of $\mathrm{NaOH}$ was pumped to the heater for the steam. It has since been found that using steam from a dilute caustic solution and probably containing entrained alkali particles gave further rate improvement with the chars that had been prepared with alkali during charring and were then water washed. Figure 3 presents some of these data. When the residual char after about $30 \%$ conversion was water extracted, small amounts of alkali were found in the extract, even though none could be found prior to gasification. This confirms that entrained alkali particles are introduced with the steam and that it is this continuous feed of alkali which enhances gasification rates.

A large volume of information was obtained for the effectiveness of tricomponent catalysts in gasifying coals and chars. Evaluation of these data is in progress and they will be presented later.

A paper Factors Affecting the Reactivity of Chars and Cokes During LowTemperature $\left(640^{\circ} \mathrm{C}\right)$ Steam Gasification was published in ENERGY AND FUELS 7, 393398 (1993) and is based on this project. 


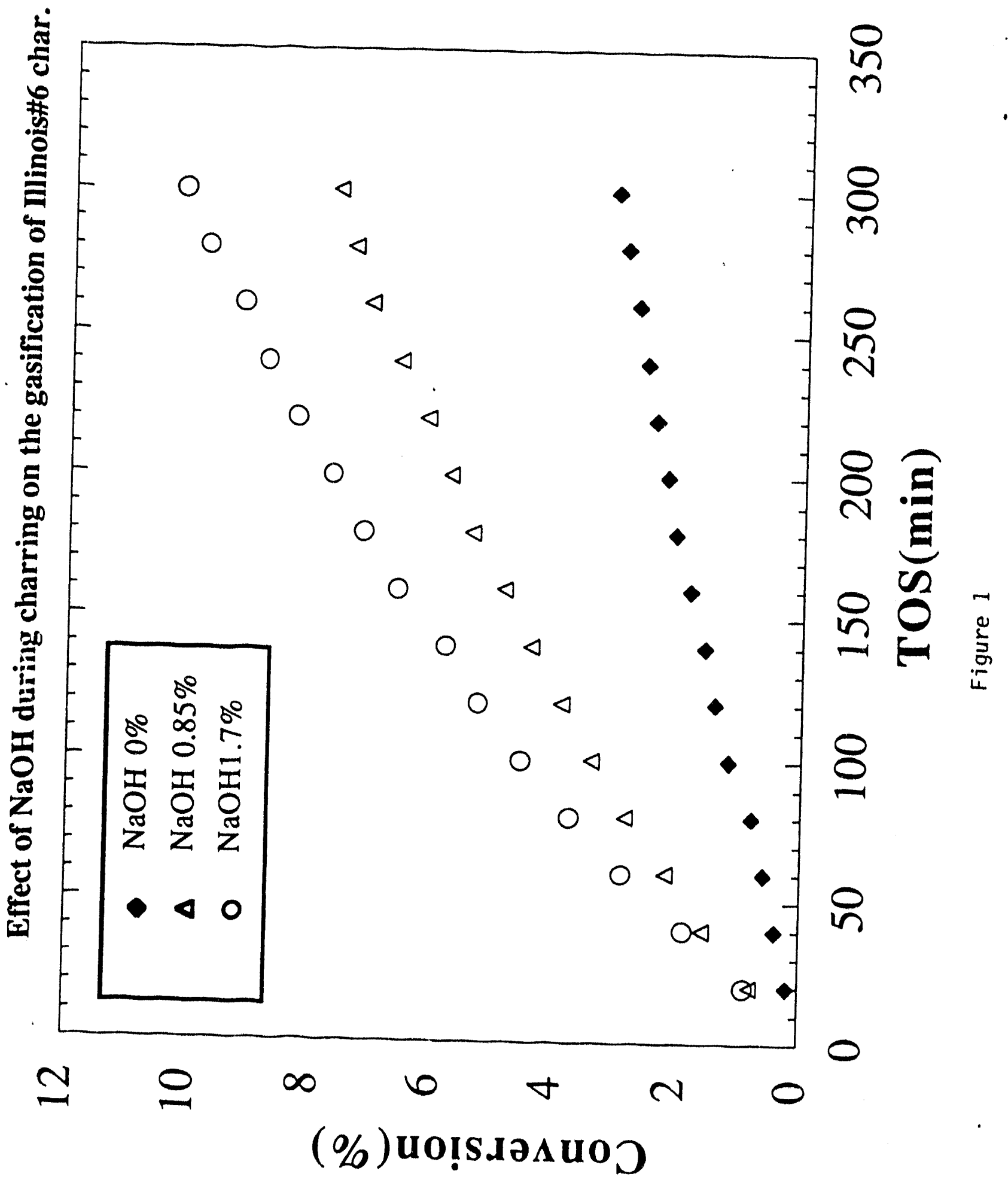




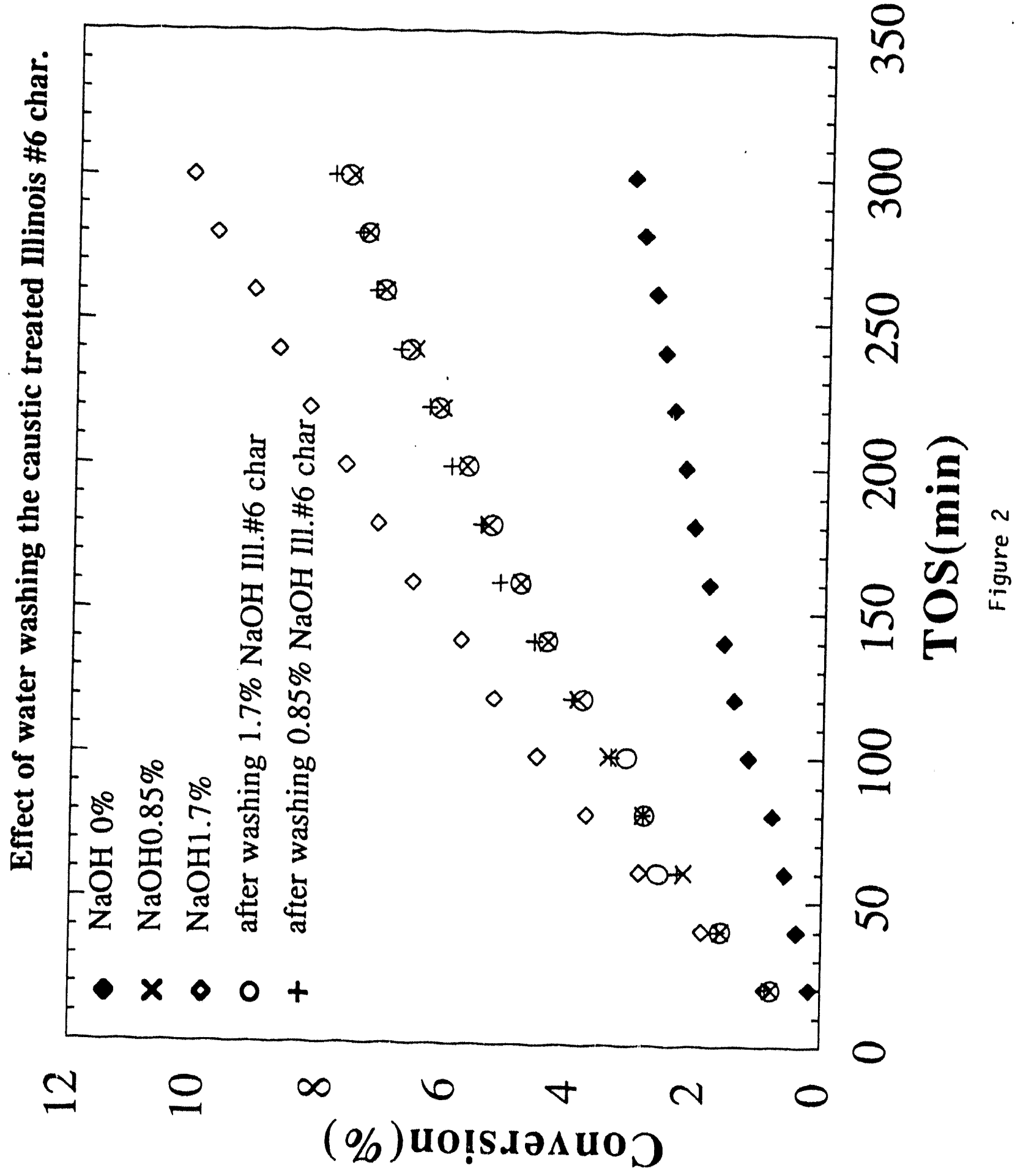




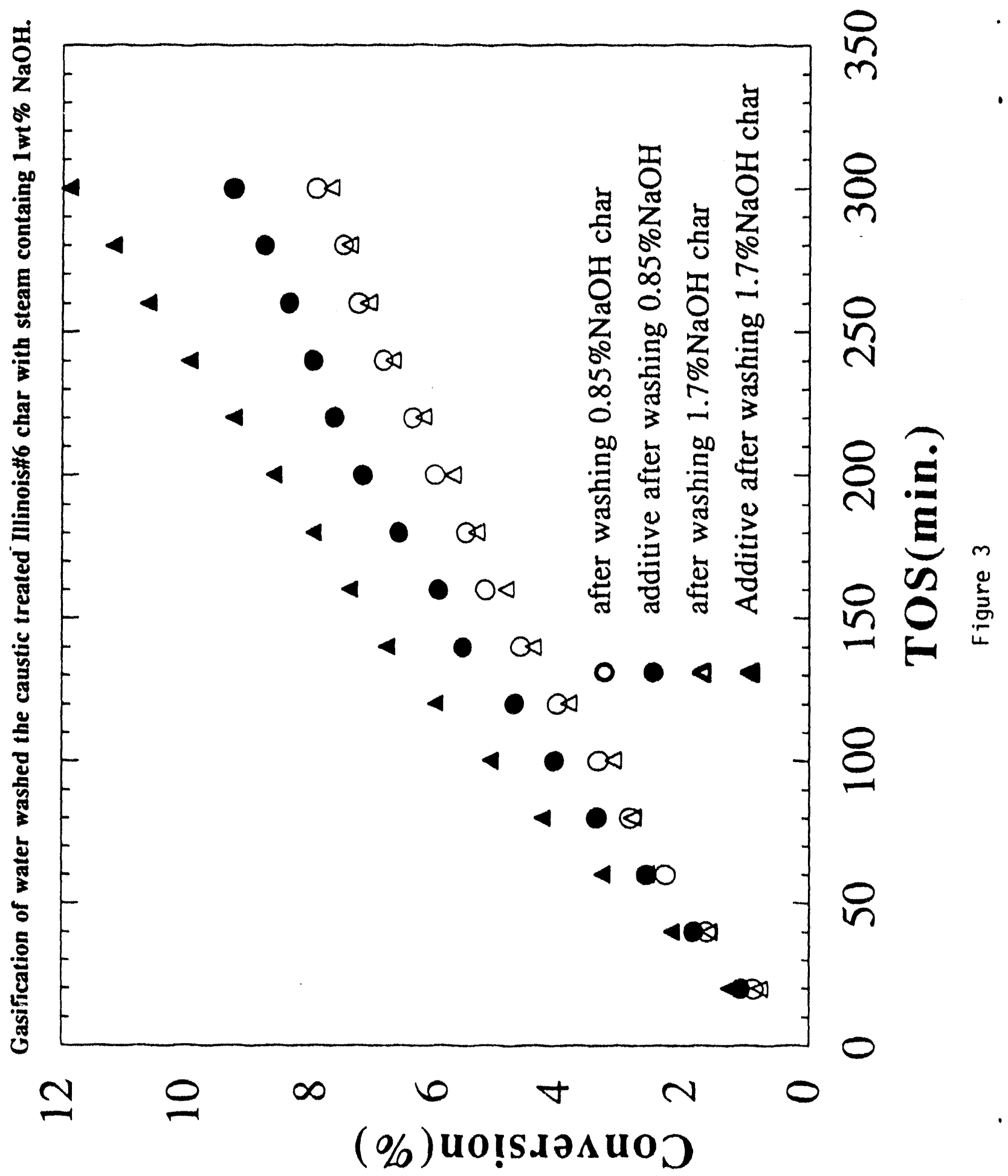


b) Oxidative Methane Coupling and Partial Oxidation of Methane

\section{Membrane Reactor}

The principles of a proton conducting membrane reactor have previously been described in the December 31, 1992, quarterly report (LBL-33241, p. 7). Subsequent reports (LBL-34250 and 33769) have detailed some of the difficulties encountered in designing and testing a workable reactor.

The prior reactor design failed to exclude external air from the reactor interior under reaction conditions, leading to air/methane mixing and complete combustion at $700^{\circ} \mathrm{C}$. A $4 \%$ yield of $C 2$ hydrocarbons was observed at $650^{\circ} \mathrm{C}$, but with much higher yield of carbon oxides. A new reactor design, incorporating an O-ring seal that sits outside the furnace, has now been tested without the membrane in place, and was successful in excluding outside air, even when the center of the furnace (where the membrane will sit) was above $800^{\circ} \mathrm{C}$.

Three different membrane materials have been prepared in powder form $\left(\mathrm{SrZr}_{0.9} \mathrm{Y}_{0.1} \mathrm{O}_{2.95}, \mathrm{CaZr}_{0.9} \mathrm{Y}_{0.1} \mathrm{O}_{2.95}\right.$, and $\left.\mathrm{SrCe}_{0.9} \mathrm{Y}_{0.1} \mathrm{O}_{2.95}\right)$. The powders are easily prepared by calcination of the respective metal oxides and alkaline earth carbonates at $1100^{\circ} \mathrm{C}$. At this temperature, the carbonates decompose and react with the other oxides to produce the perovskite materials, which has been confirmed by $X$-ray diffraction.

Membrane fabrication from the powders has been less successful. These oxide powders must be pressed into preforms and sintered at high temperatures $\left(>1500^{\circ} \mathrm{C}\right)$ to obtain membranes with adequate density for use (preferred $>90 \%$ of theoretical density, or $<10 \%$ porosity). At these temperatures, the perovskites react with the alumina pedestal in the sintering furnace to form aluminates, which then melt. The $\mathrm{Zr}$-based perovskites must be sintered at $\geq 1650^{\circ} \mathrm{C}$. Reaction with alumina was avoided by placing a tungsten plate on the pedestal during sintering. A sintered cylindrical preform ( $\mathrm{SrZr}_{0.9} \mathrm{Y}_{0.1} \mathrm{O}_{2.95}, 16 \mathrm{~mm}$ diameter) was obtained with $\sim 85 \%$ of theoretical density. Half of it was sliced into $1 \mathrm{~mm}$ thick disk membranes. The $\mathrm{Ce}$ based material has a lower melting temperature due the weaker $\mathrm{Ce}-\mathrm{O}$ bond relative to the $\mathrm{Zr}-\mathrm{O}$ bond. $\mathrm{A} \mathrm{SrCe} \mathrm{S}_{0.9} \mathrm{Y}_{0.1} \mathrm{O}_{2.95}$ cylinder with $\sim 90 \%$ of theoretical density was obtained after sintering at only $1500^{\circ} \mathrm{C}$. It was difficult, but not impossible, to slice this cylinder into disks, as the weaker bonding also made the material more brittle.

One of the $\mathrm{SrZr}_{0.9} \mathrm{Y}_{0.1} \mathrm{O}_{2.95}$ disks was sealed into the redesigned reactor with a silica-based high temperature paste and tested for reactivity. A tiny crack in the membrane allowed a small amolint of intermixing of gases across the membrane, which increased with increasing temperature. Feed flows were $6.9 \mathrm{cc} / \mathrm{min}$ (STP) of $\mathrm{O}_{2}$ to one side, and 1.0 and $21.7 \mathrm{cc} / \mathrm{min}$ (STP) of $\mathrm{CH}_{4}$ ar d He to the other side. Methane leaked to the oxygen side and reacted to form some coupling products and $\mathrm{CO}_{x}$ at a reactor temperature of $600^{\circ} \mathrm{C}$. Oxygen leaked to the methane side and reacted to convert methane to coupling products (up to $3.5 \%$ yield) but also much 
more $\mathrm{CO}_{x}\left(>20 \%\right.$ yield) at a reactor temperature of $700^{\circ} \mathrm{C}$. At this temperature, the residual methane:oxygen ratio on the methane side was $-1: 4$. At $750^{\circ} \mathrm{C}$, all the methane reacted, producing only $\mathrm{CO}_{\mathbf{x}}$.

A crack-free $\mathrm{SrCe}_{0.9} \mathrm{Y}_{0.1} \mathrm{O}_{2.95}$ disk (as discerned from magnified visual inspection) has been installed and is ready for testing.

\section{Methane Partial Oxidation}

The data presented in the previous quarterly report (LBL-34250) have been incorporated in a paper which has been accepted for publication in CATALYSIS LETTERS.

A new approach to partial oxidation has been undertaken. This involves a two-step consecutive catalytic operation in which methane is decomposed at low temperature to carbon and hydrogen in the first step and the residual carbonaceous deposition the catalyst is in the second step gasified with steam to give syngas or hydrogenated to give higher hydrocarbons; e.g., ethane, ethylene, or $C_{3+}$. A reactor system has been designed and fabricated and experimental exploratory work is underway. Results are too fragmentary to report at this time.

\section{c) Synthesis and Characterization of Catalysts}

Films have been made that can be used to coat reactor parts such as screws, rods, and other reactor part surfaces. These films include those contining calcium-nickel oxide as well as calcium-nickel-potassium oxide phases, and partial characterization of the films has been conducted. In the case of the solid-solution films of calcium-nickel oxide films for example, it was possible to form films of variable composition by using sintered targets of $\mathrm{CaO}$ and $\mathrm{NiO}$. X-ray diffraction studies showed the lattice constants for each film varied as a function of the stoichiometry of the individual films. The film preparation technique has been shown to be ab le to reproducibly form different films of desired metal stoichiometries.

A manuscript of the variable-composition deposition/formation studies has been submitted for publication.

Magnetochemical studies have been continued with regard to using this experimental approach to study the electronic and magnetic differences among different catalysts. Magnetic data were studied for each catalyst as a function of synthetic preparative route, annealing temperatures and times, and the source of the species that could possibly contribute to the magnetic effects exhibited by each bulk catalyst.

A manuscript that details this work is currently in preparation. 


\title{
$\mathrm{Ca}_{(1 \cdot x)} \mathrm{Ni}_{x} \mathrm{O}$ Catalytic Thin Films Prepared by Pulsed Laser Deposition
}

\author{
X.L. Mao, D.L. Perry ${ }^{a)}$, and R.E. Russo ${ }^{a)}$ \\ Lawrence Berkeley Laboratory, Berkeley, CA 94720
}

\begin{abstract}
$\mathrm{Ca}_{(1-x)} \mathrm{Ni}_{\mathrm{x}} \mathrm{O}$ solid-solution films with varying stoichiometry have been prepared by pulsed laser deposition from sintered targets of $\mathrm{NiO}$ and $\mathrm{CaO}$. Xray diffraction data indicate that the structure of the films is that of the sodium chloride structure. The lattice constants for different stoichiometries vary with film composition. Using the Madelung energy as the binding energy between anions and cations, and assuming that nickel and calcium ions are distributed randomly in lattice sites, the lattice constants were calculated and found to compare with experimental results. This study investigated the compositional changes that occur during the target sintering process and the pulsed laser deposition of films. Using these data, a target composition can be prepared to produce $\mathrm{Ca}_{(1-\mathrm{x})} \mathrm{Ni}_{\mathrm{x}} \mathrm{O}$ thin films with any desired lattice constant.
\end{abstract}

a) Authors to whom correspondence can be addressed. 


\section{INTRODUCTION}

Recent reports in the literature have described the use of calcium-nickel oxides doped with potassium for the oxidative coupling of methane. ${ }^{1-4}$ This material, prepared from a combination of various oxides and salts of the parent elements, is polycrystalline and can vary substantially as a function of its preparative route. The choice of starting compounds, annealing temperatures, and annealing times markedly affects the resulting product. One of the chief reason for this is the high volatility of the potassium oxide phase relative to the calcium and nickel phases. In general, quaternary metal oxides are often difficult to prepare easily, reproducibly, and directly by thermal decomposition and annealing of a mixture of the metal-containing powders. It would be, therefore, highly advantageous to develop a method for the fabrication of these materials by which the potassium could be homogeneously and reproducibly incorporated into the solid phase with the calcium and nickel. Also, the fabrication of these materials as films will make possible detailed studies of both the interaction between the calcium-nickel oxide set with potassium and the interaction between these metal oxide systems and gases such as methane. Such reaction experiments are essential and require a basic understanding of the calcium-nickel oxide host system.

In this paper, the authors report the fabrication of oriented $\mathrm{Ca}_{(1-x)} \mathrm{Ni}_{\mathrm{x}} \mathrm{O}$ solid-solution films with varying stoichiometry from sintered targets of $\mathrm{NiO}$ and $\mathrm{CaO}$. The pulsed laser deposition method for growing thin films has recently been applied to a large class of materials, including semiconductors 5.8 , insulators 9 , high temperature superconductors ${ }^{10-14}$, and diamond-like films ${ }^{15,16}$. This new deposition process involves the interaction 
of a pulsed laser beam with any type of target, the formation of a plasma plume, and the deposition of the plume materials on a heated substrate. By using a short pulse-width laser beam with high power density at the target suriace, the materials are instantly vaporized and partially ionized. The temperature of the plasma can be $10^{3}-10^{7} \mathrm{~K} .{ }^{17}$ The elements from a compound target are mixed in the plume. When the vaporized materials are deposited on a substrate, the composition and structure of the film can be different than that of the original target. By changing the target composition one can fabricate a "solid solution" film with varying stoichiometry. Pulsed laser deposition is a powerful technique for making new compound films which are difficult to produce using traditional high temperature sintering processes. The $\mathrm{Ca}_{(1-\mathrm{x})} \mathrm{Ni}_{\mathrm{x}} \mathrm{O}$ solid-solution films cannot be fabricated from the solid reaction of $\mathrm{NiO}$ and $\mathrm{CaO}$ at $900^{\circ} \mathrm{C}$.

\section{EXPERIMENTAL}

Bulk targets were made from high purity $\mathrm{CaO}$ and $\mathrm{NiO}$ powders. The targets had a nominal composition of $\mathrm{Ca}_{(1-\mathrm{x})} \mathrm{Ni}_{\mathrm{x}} \mathrm{O}(\mathrm{x}=0.1,0.2,0.5,0.65,0.8$, $0.9)$. After mixing and grinding the powder in an agate mortar, targets were pressed under 20,000 psi and sintered at $900^{\circ} \mathrm{C}$ for 64 hours.

The $\mathrm{Ca}_{(1-\mathrm{x})} \mathrm{Ni}_{\mathrm{x}} \mathrm{O}$ thin films were fabricated by pulsed excimer laser deposition in a vacuum chamber. The experimental setup was described in detail earlier10; only a brief summary is presented here. The laser was operated at a $5 \mathrm{~Hz}$ repetition rate with $350 \mathrm{~mJ} /$ pulse. The laser beam was incident on the targets at an angle of $45^{\circ}$, with an energy density of about 5 $\mathrm{J} / \mathrm{cm}^{2}$. The oxygen pressure and substrate temperature during deposition were 
$10 \mathrm{mTorr}$ and $600^{\circ} \mathrm{C}$, respectively. $\mathrm{MgO}$ single crystals (100) were used as substrates for film deposition. The distance between target and substrate was 4 cm. After 15 minutes of deposition, the $\mathrm{Ca}_{(1-\mathrm{x})} \mathrm{Ni}_{\mathrm{x}} \mathrm{O}$ thin film thickness was approximately $1500 \AA$. When the deposition was finished, the films were cooled to room temperature at 10 mTorr within half an hour.

The structures of films and targets were characterized by $x$-ray diffractometry with a $\mathrm{Cu} \mathrm{K} \alpha$ source. The compositions of films and targets were measured by energy dispersive $x$-ray spectroscopy (EDX).

\section{RESULTS AND DISCUSSION}

Figure 1 shows $2 \theta$-ray diffraction data for $\mathrm{Ca}_{(1-\mathrm{x})} \mathrm{Ni}_{\mathbf{x}} \mathrm{O}$ thin films made from the different targets. The $x$ value in Figure 1 is determined from the composition of each film measured by EDX. The peak at $43^{\circ}$ is the $\mathrm{MgO}(200)$ substrate diffraction. The peaks located from $37^{\circ}$ to $42^{\circ}$ belong to the films. The d-values of these peaks are $2.195 \AA, 2.273 \AA$ and $2.332 \AA$ for $x$ equal to $0.78,0.43,0.30$, respectively. From Figure 1, the larger the value of $x$, the lower the $d$-value of the films. $\mathrm{CaO}$ and $\mathrm{NiO}$ exhibit the sodium chloride structure, and the d-values for the (200) peak of $\mathrm{CaO}$ and $\mathrm{NiO}$ are $2.398 \AA$ and $2.083 \AA$, respectively. Because the $d$-values of the films are between those of $\mathrm{CaO}$ and $\mathrm{NiO}$, it is likely that the structure of composite films would also be that of sodium chloride. In order to confirm the structure, the films were tilted $45^{\circ}$ for the $x$-ray diffraction measurements. In this configuration, the (220) peaks of the $\mathrm{MgO}$ substrate and the film should appear. Figure 2 shows these $x$-ray diffraction data for the same three films used in Figure 1. Again, except for the (220) peak of $\mathrm{MgO}$, there is only one peak for each film. The 
$\mathrm{d}$-values of the peaks are $1.559 \AA, 1.626 \AA$ and $1.655 \AA$ corresponding to $x=0.78,0.43$ and 0.30 , respectively. This experiment confirms that the film structure is that of sodium chloride. Because there is only the (200) peak of films in x-ray diffraction data, the $\mathrm{Ca}_{(1-x)} \mathrm{Ni}_{\mathbf{x}} \mathrm{O}$ thin films deposited on $\mathrm{MgO}$ single crystal are oriented.

From the d-values measured in Figure 1 and 2, the lattice constant of films, fabricated using the different target compositions, can be obtained. The lattice constant of the films measured is between that of $\mathrm{CaO}$ and $\mathrm{NiO}$, indicating that the $\mathrm{Ca}_{(1-\times)} \mathrm{Ni}_{\mathrm{x}} \mathrm{O}$ thin films are a solid solution of $\mathrm{NiO}$ and $\mathrm{CaO}$. In order to support this argument, one can use the Madelung energy 18 as the binding energy for $\mathrm{Ni}-\mathrm{O}$ and $\mathrm{Ca}-\mathrm{O}$ ions and calculate the lattice constant versus $\mathrm{x}$.

The interaction energy $U_{i j}$ between ion $i$ and ion $j$ can be expressed as ${ }^{18}$ :

$$
U_{i j}=\lambda e^{-r_{i j} / \rho} \pm \frac{q^{2}}{r_{i j}}
$$

where $\lambda$ and $\rho$ are empirical parameters that are determined from the lattice constant and compressibility. The distance between ion $i$ and $j$ is $r_{i j}$ and $q$ is the electrical charge of the ions. The first term of the equation is a central field repulsive potential between ion cores, and the second term is a coulomb potential. 
If one includes the repulsive interaction only among nearest neighbors and assume that nickel and calcium ions are randomly arranged in lattice sites, the total energy of the crystal lattice is:

$$
U=N\left[x\left(\lambda_{N i} Z e^{-R / P_{M}}-\frac{\alpha q^{2}}{R}\right)+(1-x)\left(\lambda_{C_{a}} Z^{-R / P_{a}}-\frac{\alpha q^{2}}{R}\right)\right]
$$

where $\mathrm{N}$ is the number of nickel and calcium ions. $\mathrm{x}$ is the stoichiometry value in $\mathrm{Ca}_{(1-\mathrm{x})} \mathrm{Ni}_{\mathrm{x}} \mathrm{O} . \mathrm{Z}$ is the number of nearest neighbors for any ion, and $\alpha$ is the Madelung constant which is equal to 1.747565 for the sodium chloride structure ${ }^{18} . R$ is the nearest-neighbor separation distance in the crystal. The subscripts $\mathrm{Ni}$ and $\mathrm{Ca}$ indicate $\mathrm{NiO}$ and $\mathrm{CaO}$ sices. At the equilibrium point, the total energy $U$ will be minimal, and $d U / d R=0$. Therefore, the nearestneighbor separation distance in a solid solution can be calculated from the following equation:

$$
\frac{1}{R^{2}}=X \frac{e^{\left(R_{N i}-R\right) / \rho_{N i}}}{R_{N i}^{2}}+(1-X) \frac{e^{\left(R_{C_{a}}-R\right) / P_{C a}}}{R_{C}^{2}}
$$

where $\mathrm{R}_{\mathrm{Ni}}$ and $\mathrm{R}_{\mathrm{Ca}}$ are nearest-neighbor separation distances in pure $\mathrm{NiO}$ and $\mathrm{CaO}$ compound, respectively.

The compressibility c can be expressed as

$$
\frac{1}{c}=-V \frac{d P}{d V}=V \frac{d^{2} U}{d V^{2}}
$$

where $\mathrm{V}$ is the volume of the crystal. By substituting the total energy into Eq. 4 and using $d U / d R=0$ to determine the lattice constant, one has: 


$$
\frac{1}{\rho}=\frac{9 a^{3}}{4 \alpha q^{2} c}+\frac{4}{a}
$$

where $a$ is the lattice constant.

Using compressibility data 19,20 and the lattice constants for $\mathrm{CaO}$ and $\mathrm{NiO}$ measured in this study, the $\rho_{\mathrm{Ca}}=0.37 \AA$ and $\rho_{\mathrm{Ni}}=0.346 \AA$ can be calculated from Eq. 5. The lattice constant for solid solutions of $\mathrm{Ca}_{(1-x)} \mathrm{Ni}_{\mathrm{x}} \mathrm{O}$ versus $\mathrm{x}$ can be calculated from Eq. 3. The curve is shown in Figure 3 with the experimentally measured value from the films produced in this study, with the agreement being quite good.

The present study investigated the compositional changes that resulted during the laser deposition and sintering processes using EDX. The compositions of sintered target versus compositions of starting material and compositions of films versus targets are shown in Figures 4 and 5 , respectively. The figures show that some of the nickel is lost during the sintering process, whereas some of the calcium is lost in the laser deposition process. The melting point of $\mathrm{NiO}$ is $1990^{\circ} \mathrm{C}$, and that of $\mathrm{CaO}$ is $2580{ }^{\circ} \mathrm{C}$, which partially explains why some nickel is lost during the sintering process. During the laser deposition process, $\mathrm{NiO}$ will be preferentially vaporized with the composition of nickel being rich in the ablated plume. The substrate temperature is only $600^{\circ} \mathrm{C}$, so the loss of nickel from the film will be negligible. Therefore, the composition of nickel in films will be richer than the target. Similar behavior was observed previously for the deposition of the $\mathrm{Bi}-\mathrm{Sr}-\mathrm{Ca}-\mathrm{Cu}-\mathrm{O}$ high temperature superconducting films. ${ }^{21}$ 
In order to verify that the loss of nickel and calcium during the process is the same for different starting compositions, the ratio of loss of nickel and calcium for different compositions was determined. Assuming the loss of nickel and calcium in a process is $\mathrm{k}_{\mathrm{Ni}}$ and $\mathrm{k}_{\mathrm{Ca}}$, respectively, the stoichiometry of the compound will change from $\mathrm{Ca}_{(1-x)} \mathrm{Ni}_{\mathrm{x}} \mathrm{O}$ to $\mathrm{Ca}_{(1-x) \mathrm{k}_{\mathrm{C}}} \mathrm{Ni}_{\mathrm{xk}_{\mathrm{Ni}}} \mathrm{O}$ during the process. One can express the stoichiometry of the compound after the process as $\mathrm{Ca}_{\left(1-x^{\prime}\right)} \mathrm{Ni}_{\mathrm{x}} \mathrm{O} . \mathrm{k}$ is defined as $\mathrm{k}_{\mathrm{Ni}} / \mathrm{k}_{\mathrm{Ca}}$, and $\mathrm{x}^{\prime}$ can be expressed as:

$$
x^{\prime}=\frac{x}{x+k(1-x)}
$$

From Figure 4 and 5, one finds the ratio of the composition lost (k) is the same for different values of $x$ using our processing conditions. The value of $k$ is 2.2 and 0.328 (determined by a least squares fit) for the sintered and laser deposition processes, respectively. A value of $\mathrm{k}$ larger than 1.0 means more nickel is lost during a process. The ratio of nickel lost from starting materials to deposited films, $k$, is equal to 0.72 . For different inter and laser deposition condition, one can measure the composition of films and determine the composition loss ratio (k) by Eq.6. Thus one can select the lattice constant one wishes, then choose the starting composition of material using Eq.6.

\section{CONCLUSION}

This study has demonstrated that $\mathrm{Ca}_{(1 \cdot x)} \mathrm{Ni}_{\mathrm{x}} \mathrm{O}$ thin films can be fabricated with various $x$ values. It has been determined that the structure of the $\mathrm{Ca}_{(1-x)} \mathrm{Ni}_{x} \mathrm{O}$ thin films is that of sodium chloride. The lattice constant will change with the composition of films. By varying the starting material 
stoichiometry, one can fabricate thin films with a selected lattice constant. For catalysis application, the lattice constant may influence the activity of the catalyst by the influence of the amount of potassium incorporated into the structure. Work is currently underway in the fabrication and characterization of potassium doped $\mathrm{NiCaO}$ thin films.

\section{ACKNOWLEDGMENTS}

The authors thank Wing Tat Chan for helpful discussion and James Wu for help in preparing the targets. This work was supported by the Assistant Secretary for Fossil Energy, Office of Technical Coordination, U.S. Department of Energy under Contract DE-AC03-76SF00098, through the Morgantown Energy Technology Center, Morgantown, West Virginia 26505. 


\section{REFERENCES}

1. P. Pereira, S.H. Lee, G.A. Somorjai, and H. Heinemann, Catal. Lett. 6 , 255 (1990)

2. J. Rasko, P. Pereira, G.A. Somorjai, and H. Heinemann, Catal. Lett. 9, 395 (1991).

3. J. Rasko, G.A. Somorjai, and H. Heinemann, Appl. Catal. A, General 84, 57 (1992).

4. D.M. Ginter, E. Magni, G.A. Somorjai, and H. Heinemann, Catal. Lett. 16, 197 (1992).

5. J.T. Cheung, G. Niizawa, J. Moyle, N.P. Ong, B.M. Paine, and T. Vreeland, Jr., J. Vac. Sci. Technol. A4,, 2086 (1986).

6. M.I. Baleva, M.H. Maksimov, S.M. Metev, and M.S. Sendova, J. Mater. Sci. Lett. 5, 533 (1986).

7. J.J. Dubowski, P. Norman, P.B. Sewell, D.F. Williams, F. Krolicki, and M. Lewicki, Thin Solid Films 147, L51 (1987).

8. H.S. Kwok, J.P. Zheng, S. Witanachchi, P. Mattocks, L. Shi, Q.Y. Ying, X.W. Wang, and D.T. Shaw, Appl. Phys. Lett. 52, 1095 (1988). 
9. H. Sankar, in Laser Controlled Chemical Processing of Surface, edited by A.W. Johnson, D.J. Ehrlich, and H.R. Schlossberg (Vorth-Holland, Amsterdam, 1984), Materials Research Society Proceedings Vol. 29, p. 373.

10. D. Dijkkamp, T. Venkatesan, X.D. Wu, S.A. Shaheen, N. Jisrawi, Y. H. Min-Lee, W.L. Mclean, and M. Croft, Appl. Phys. Lett., 51, 619 (1987).

11. J. Narayan, N.Biunno, R. Singh, O.W. Holland, and O. Auciello, Appl. Phys. Lett. 51, 1845 (1987).

12. D.K. Fork, J.B. Boyce, F.A. Ponce, R.I. Johnson, G.B. Anderson, G.A.N. Connell, C.B. Eom, and T.H. Geballe, Appl. Phys. Lett. 53, 337 (1988).

13. M.Balooch, D.R. Olander, and R.E. Russo, Appl. Phys. Lett. 55, 197 (1989).

14. X.L. Mao, R.E. Russo, H.B. Liu, and J.C. Ho, Appl. Phys. Lett. 57, 2591 (1990).

15. C.L. Marquardt, R.T. Williams, and D.J. Nagel, Mater. Res. Soc. Symp. Proc. 38, 325 (1985).

16. S.S. Wagal, E.M. Juengerman, and C.B. Collins, Appl. Phys. Lett. 53 , 187 (1988). 
17. R.K. Singh and J. Narayan, Phys. Rev. B41, 8843 (1990).

18. C. Kittel, in Introduction to Solid State Physics (John Wiley \& Son, Inc, New York, 1976), p 84.

19. E.A. Perez-Albuerne and H.G. Drickamer, J. Chem. Phys. 43, 1381 (1965).

20. R.L. Clendenen and H.G. Drickamer, J. Chem. Phys. 44, 4223 (1966).

21. Wing-Tat Chan, X.L. Mao, and R E. Russo, Appl. Spectrosc. 46, 1025 (1992). 


\section{FIGURE CAPTIONS:}

Figure 1: $2 \theta \mathrm{X}$-ray diffraction patterns in $30^{\circ}$ to $60^{\circ}$ range from $\left.\mathrm{Ca}_{(1-\times)}\right) \mathrm{Ni}_{\mathrm{x}} \mathrm{O}$ films fabricated from different targets. The substrate is single crystal $\mathrm{MgO}$.

Figure 2: $2 \theta \mathrm{X}$-ray diffraction patterns from the same $\mathrm{Ca}_{(1-\times)} \mathrm{Ni}_{\mathbf{x}} \mathrm{O}$ films in Figure 1 with the samples tilted $45^{\circ}$. The peaks are (220) sodium chloride structure.

Figure 3: Lattice constant of $\mathrm{Ca}_{(1-\times)} \mathrm{Ni}_{\mathbf{x}} \mathrm{O}$ films versus $\mathrm{x}$. The solid curve is calculated from the Madelung energy model (see text for discussion).

Figure 4: Compositional change of target during sintering process at $900^{\circ} \mathrm{C}$. The solid curve follows $\mathrm{Eq} .6 . \mathrm{k}=\mathbf{2 . 2}$.

Figure 5: Compositional change of films and target during laser deposition process. The solid curve follows Eq.6. $\mathrm{k}=0.328$. 


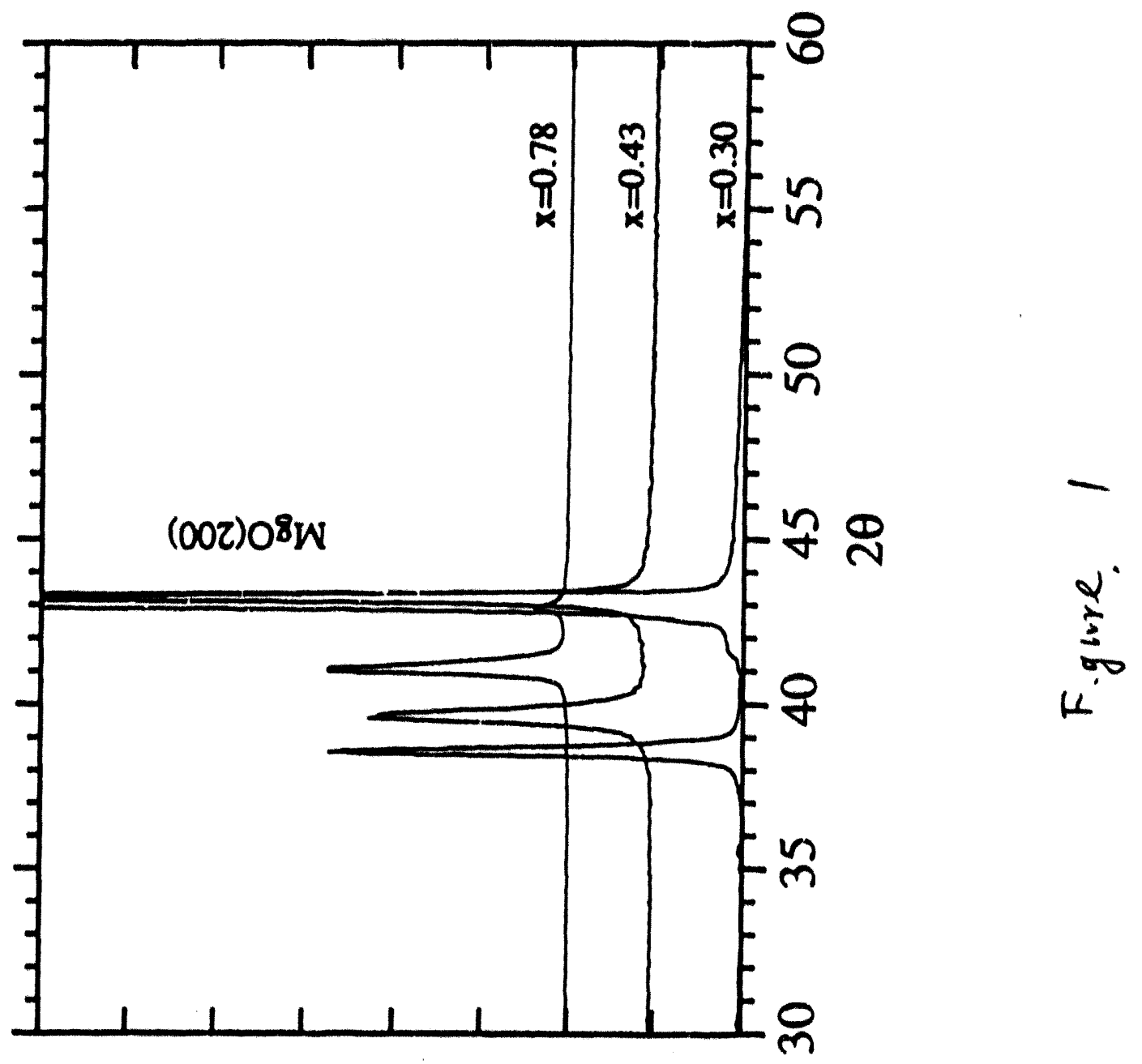

Kฺ!ฺนวนวน 


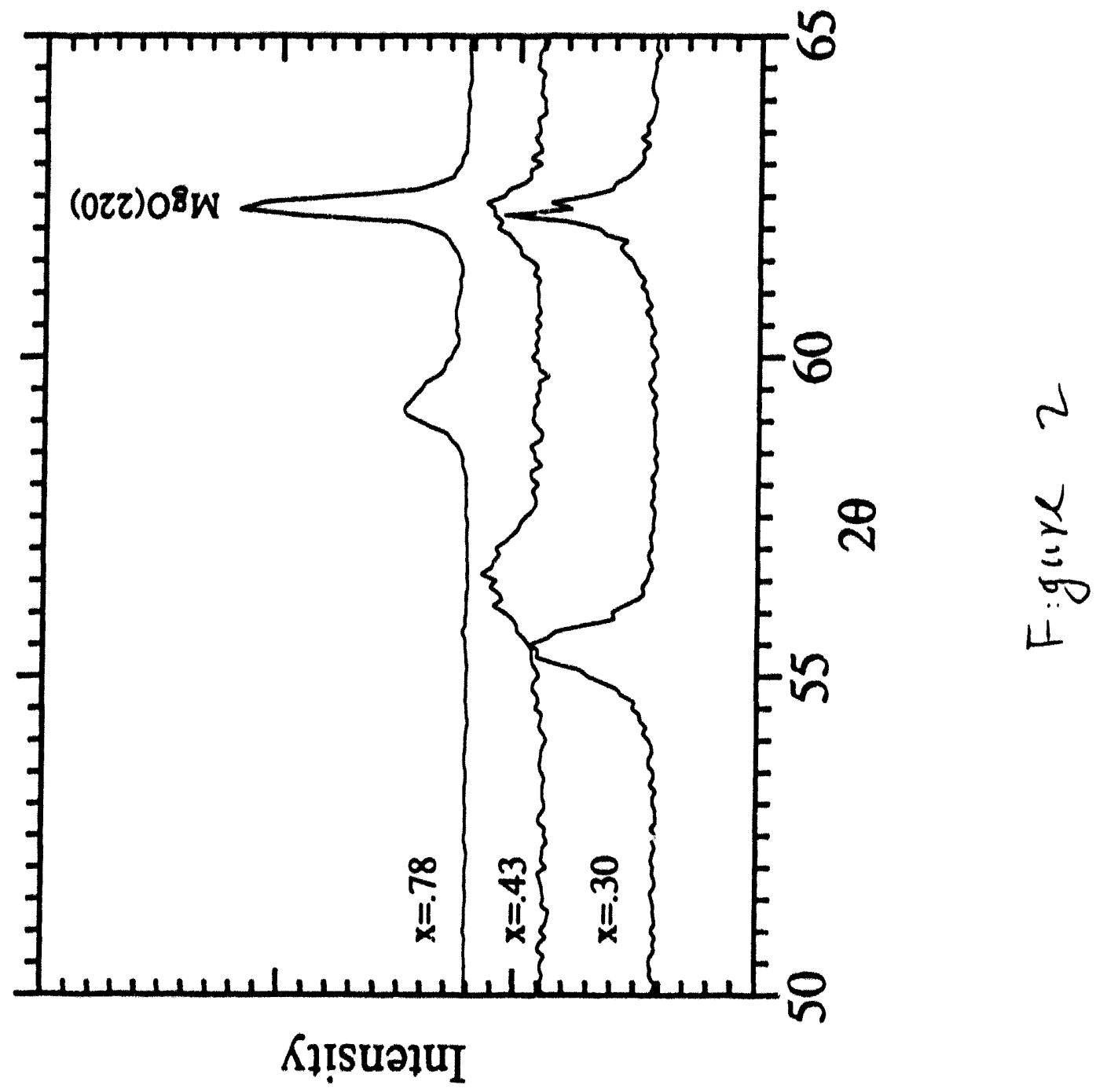




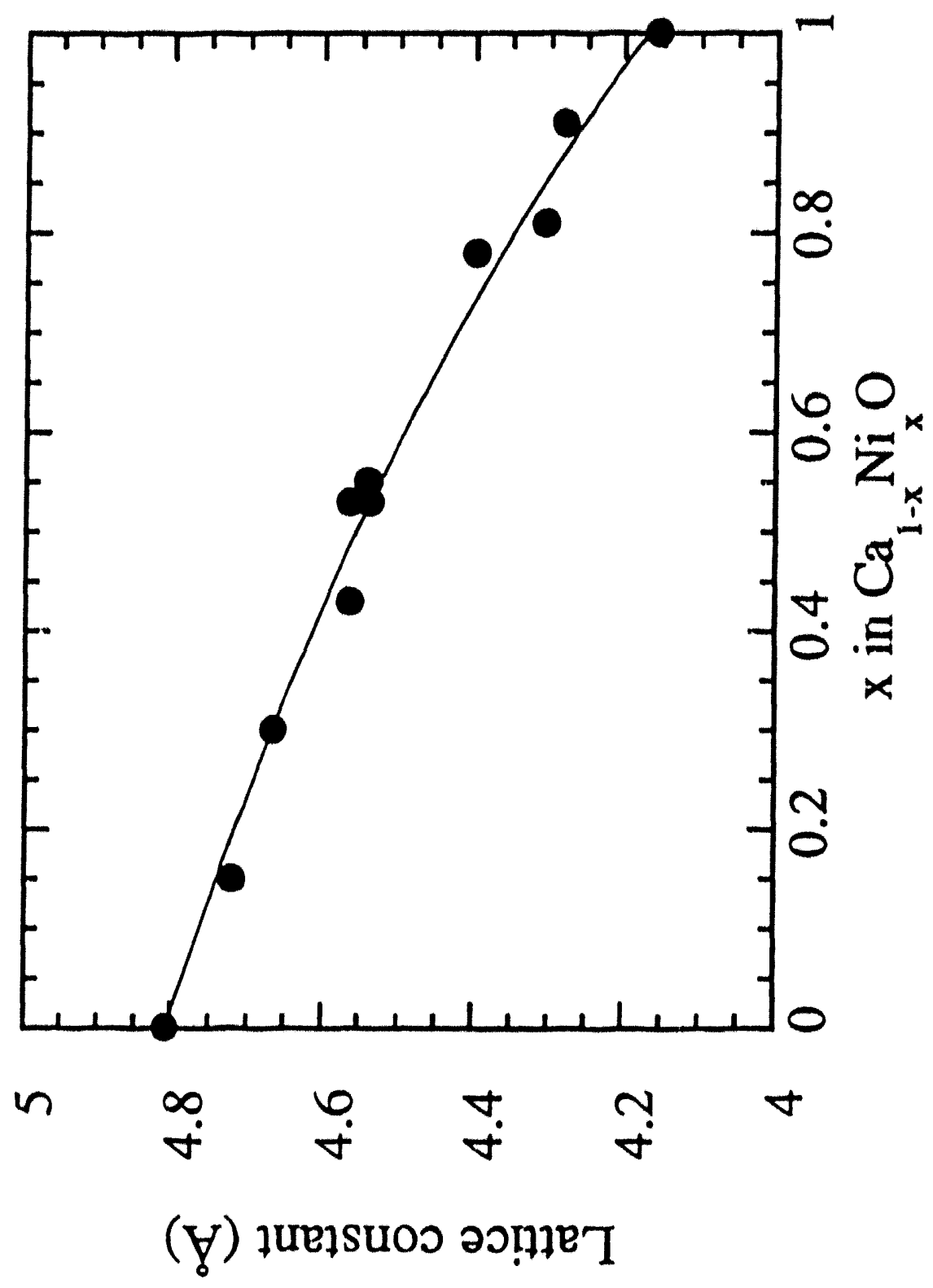

$M$

$\frac{1}{6}$ 11 


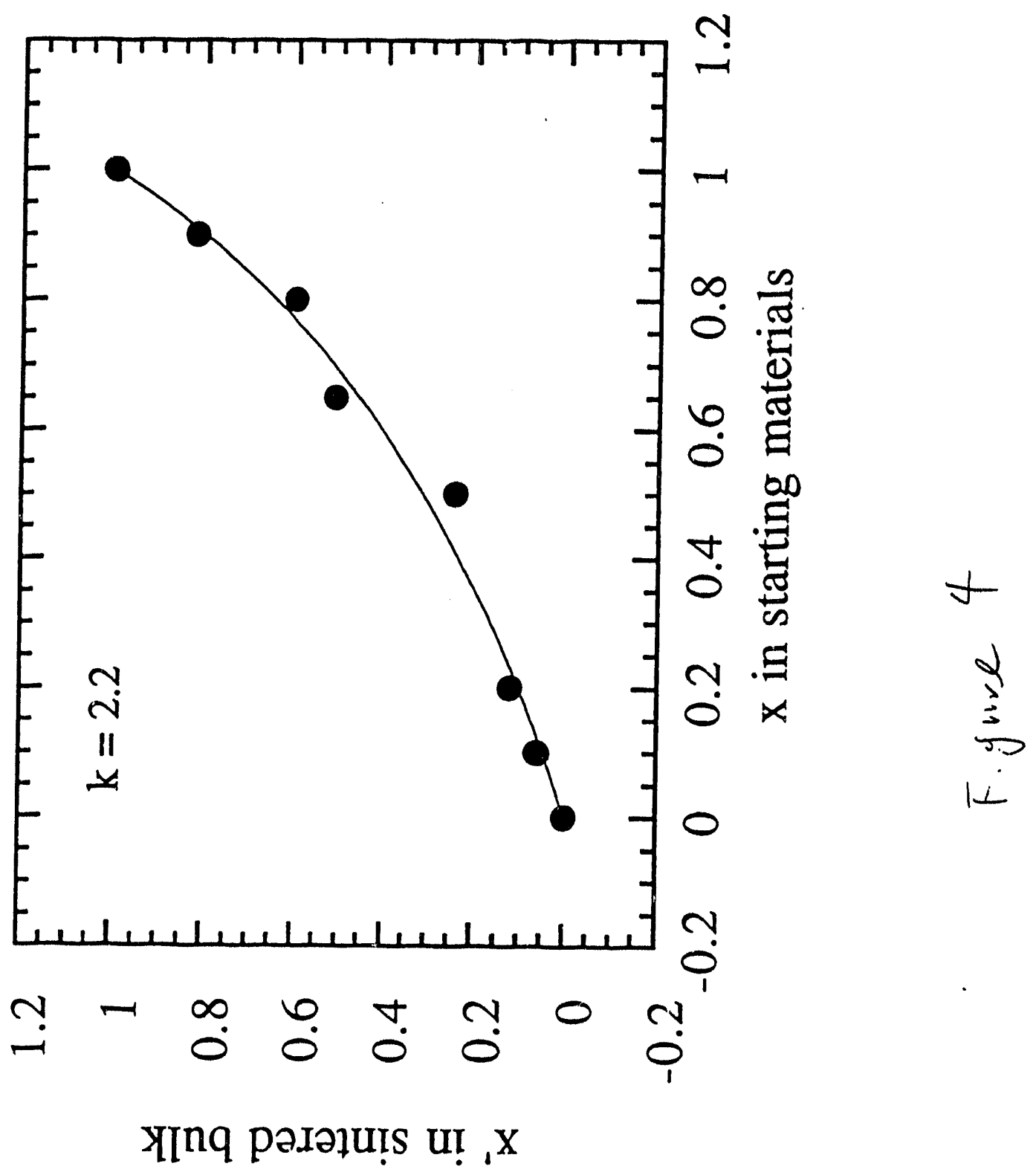




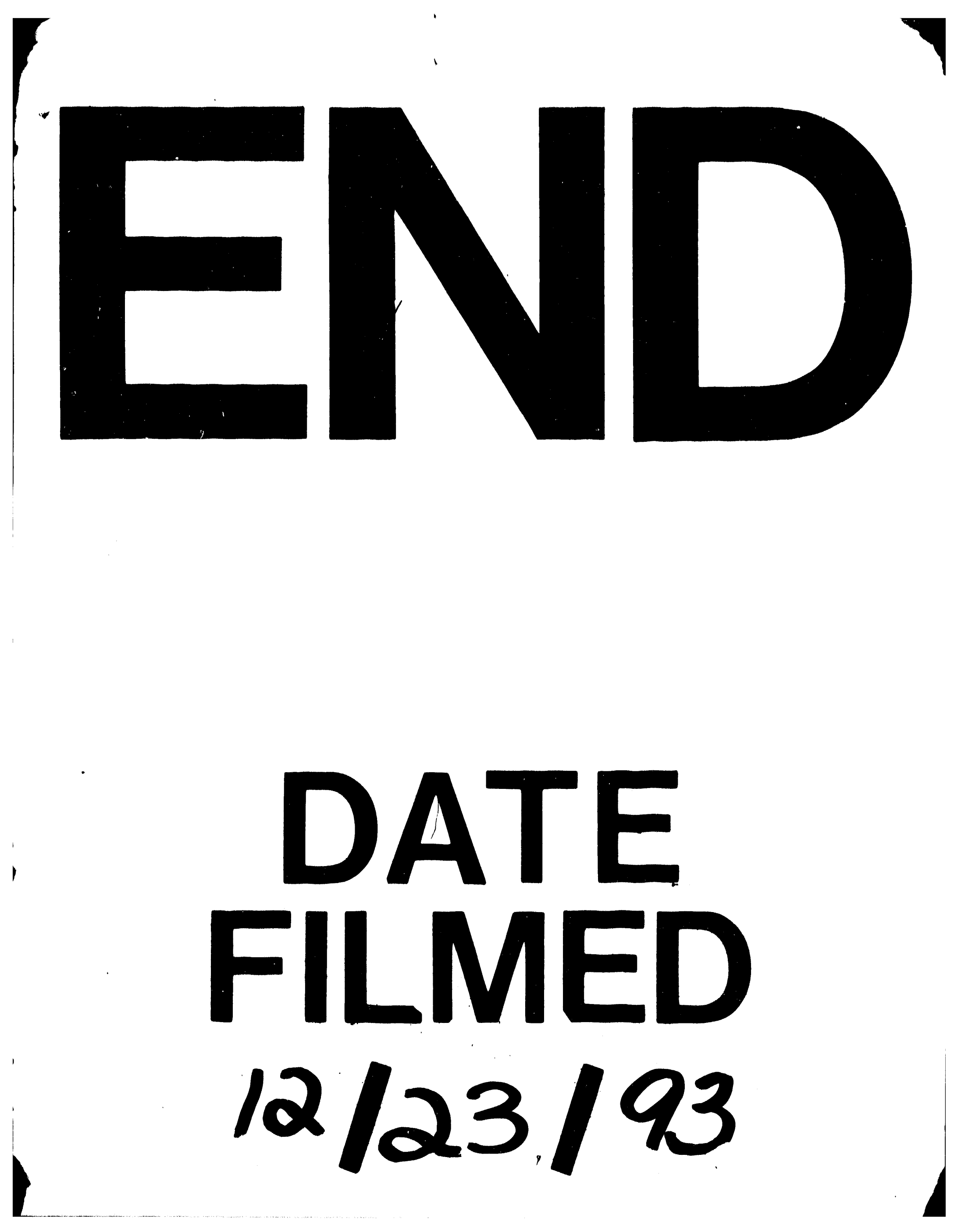




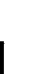

(

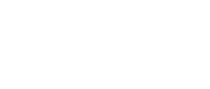

(2)

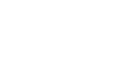

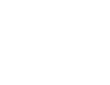

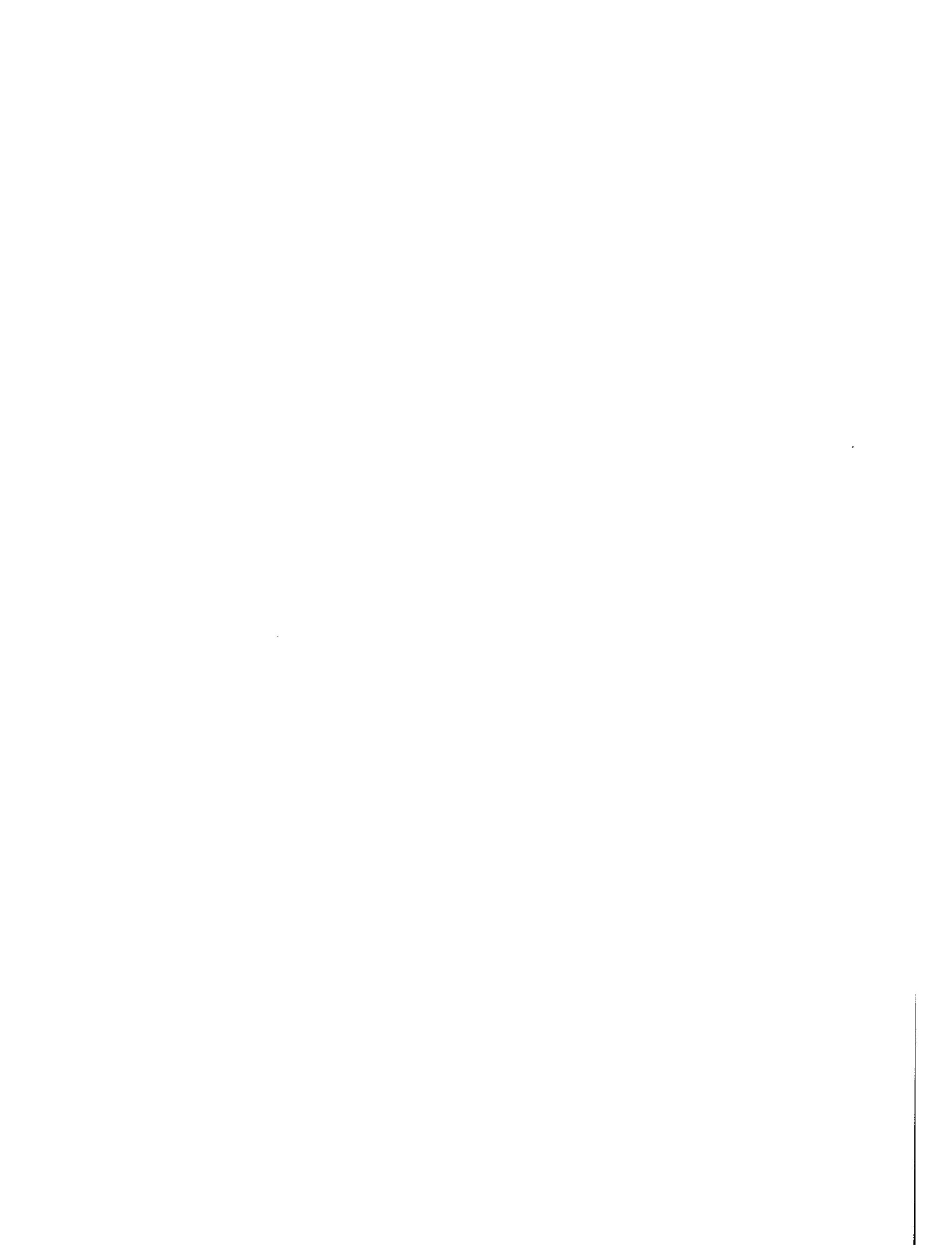

